\title{
Perancangan Aplikasi Sistem Antrian Calon Perserta Pemilihan Dengan Menggunakan Metode Single Channel Single Phase
}

\author{
Hani Anhar Nasution ${ }^{1}$, Husni Lubis ${ }^{2}$, Edrian Hadinata ${ }^{3}$ \\ Program Studi Sistem Informasi, Universitas Harapan Medan \\ Jl. H. M. Jhoni No. 70 C Medan \\ Email : hanyanharnasution@gmail.com ${ }^{1}$, husni.lubis82@gmail.com² ${ }^{2}$ edrianhadinata@gmail.com ${ }^{3}$
}

\begin{abstract}
Abstrak - Antrian (Queuing) adalah kejadian yang sering dijumpai dalam kehidupan sehari-hari. Menunggu didepan loket untuk mendapatkan tiket, menunggu pengisian bahan bakar, menunggu pintu dijalan tol, dan beberapa kasus menunggu lain sering ditemui atau mungkin dialami. Pada pemilihan kepala daerah di setiap daerah di indonesia memiliki respon yang sangat besar dari masyarakat dan antusias masyarakat untuk memilih salah satu calon bakal kepala daerah yang di inginkan, pada temuan setiap TPS (tempat pemungutan suara) tidak memiliki sistem antrian yang baik karena belum adanya pengunaan sistem aplikasi antrian pada setiap TPS. Metode single channel atau single phase bertujuan untuk mencari penyelesaian yang efektif dari kasus antrian dengan satu antrian dan satu pelayanan. Dengan adanya sistem antrian ini diharapkan dapat menjadi sebuat model antrian yang dapat mengurangi penumpukan di tempat pemilihan
\end{abstract}

Kata kunci: Antrian, Loket, TPS, Pemilihan, Metode SCSP

\section{Pendahuluan}

Antrian (Queuing) adalah kejadian yang sering dijumpai dalam kehidupan sehari-hari. Menunggu didepan loket untuk mendapatkan tiket, menunggu pengisian bahan bakar, menunggu pintu dijalan tol, dan beberapa kasus menunggu lain sering ditemui atau mungkin dialami[1][9].

Pada pemilihan kepala daerah di setiap daerah di indonesia memiliki respon yang sangat besar dari masyarakat dan antusias masyarakat untuk memilih salah satu calon bakal kepala daerah yang di inginkan, pada temuan setiap TPS (tempat pemungutan suara) tidak memiliki sistem antrian yang baik karena tidak adanya pengunaan sistem aplikasi antrian pada setiap TPS hal ini dapat menyebabkan kesulitan untuk panitia TPS yang berjaga di setiap TPS karena sistem manual yang digunakan tidak lagi efisien dalam membuat antrian yang mana masyarkat yang dapat sangat banyak.

Metode single channel atau single phase bertujuan untuk mencari penyelesaian yang efektif dari kasus antrian dengan satu antrian dan satu pelayanan[2][10]. Distribusi poisson dan distribusi eksponensial memainkan peran penting dalam analisis antrian. Distribusi mencirikan sarana pelayanan baik kedatangan maupun pelayanan sepenuhnya bersifat acak (random)[3][11]. Situasi yang dianalisis adalah faktor kegunaan bagi pelayan, panjang antrian dalam sistem, panjang antrian dalam antrian, pelayanan waktu menunggu perkiraan dalam sistem, dan waktu menunggu yang diperkirakan dalam antrian pelayanan.

\section{Tinjauan Pustaka}

Antrian merupakan suatu garis tunggu dari pengguna (satuan) yang memerlukan layanan dari satu atau lebih pelayan (fasilitas layanan). Pada umumnya, sistem antrian dapat diklasifikasikan menjadi sistem yang berbeda-beda, dimana teori antrian sering diterapkan secara luas untuk memberikan suatu disiplin dalam menerima suatu layanan[4][12].

Single channel merupakan sistem pelayanan yang memiliki satu jalur atau satu pelayanan.Sedangkan single phase adalah hanya memiliki satu stasiun pelayanan sehingga setelah menerima pelayanan dapat langsung keluar dari sistem antrian[5][13].

\section{Metode Penelitian}

Tahap Analisa sistem merupakan tahapan penguraian suatu sistem informasi utuh ke bagian komponenkomponennya dengan maksud untuk mengidentifikasi dan mengevaluasi permasalahan penelitian, kesempatan penyelesaian, hambatan-hambatan yang terjadi, dan kebutuhan-kebutuhan yang diharapkan sehingga dapat diusulkan perbaikan untuk menghasilkan sistem yang baru[6][14].

Permasalahan pada penelitian ini mengenai antrian pelayanan pemilihan pemimpin daerah. Pada temuan setiap TPS (tempat pemungutan suara) tidak memiliki sistem antrian yang baik karena tidak adanya pengunaan sistem aplikasi antrian pada setiap TPS hal ini dapat menyebabkan kesulitan untuk panitia TPS yang berjaga di setiap TPS karena sistem manual yang digunakan tidak lagi efisien dalam membuat antrian yang mana masyarkat yang datang sangat banyak pada waktu yang bersamaan. 


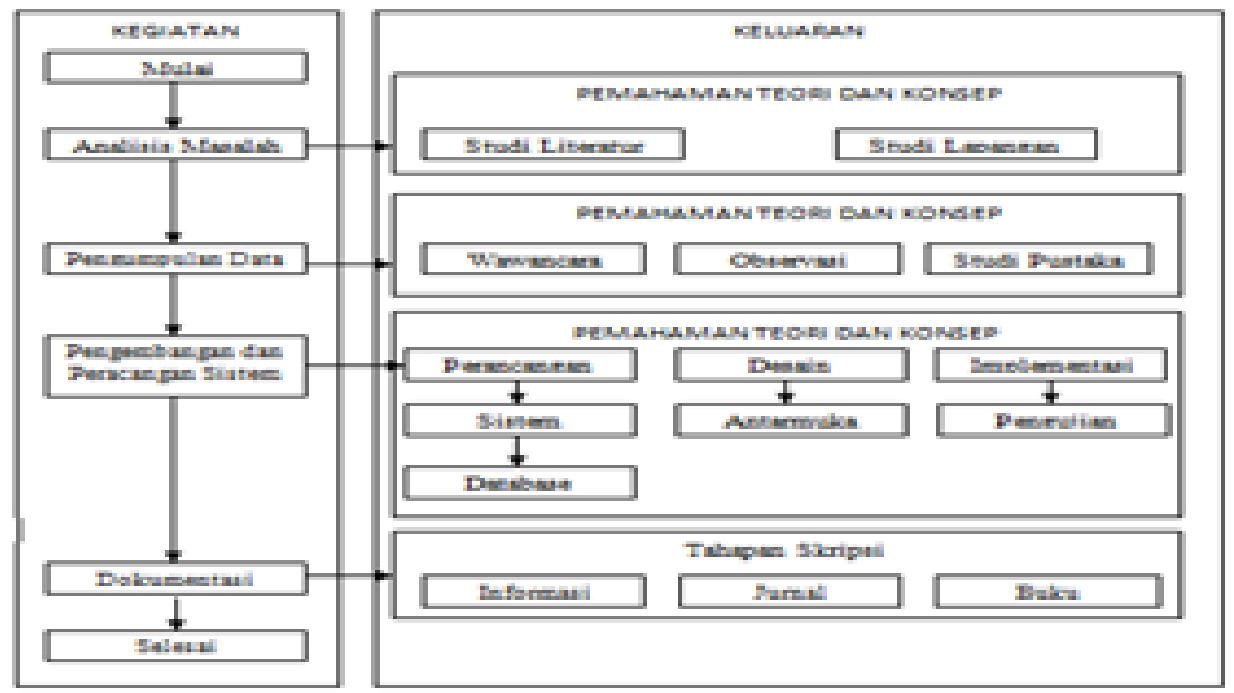

Gambar 1. Kerangkan Kerja Penelitian

Model Single Channel Single Phase merupakan model pelayanan yang hanya ada satu jalur yang memasuki sistem pelayanan dan ada satu pelayanan saja. Dalam model ini data yang digunakan adalah data kuantitatif, yaitu berupa angka data waktu kedatangan dan data waktu pelayanan dengan sumber data yang digunakan dalam penelitian ini berupa data primer, yaitu data- semedata yang diambil langsung dari objek penelitin. Banyak jalur dengan tahap pelayanan antrian (Single Channel Single Phase)[15].



Gambar 2. Sistem Single Channel Single Parse

Banyak antrian pada suatu sistem pelayanan terdiri dari 6 peserta, 1 operator pelayanan dengan 1 petugas pendata masyarakat yang berada di tempat.

Contoh Penyelesaian :

Rata-rata orang yang antri dalam sistem menggunakan rumus pada persamaan (2) yaitu :

Ket : Ls $=$ Rata-rata yang antri dalam sistem

$\lambda=2$

$\mu=6$

$\mathrm{Ls}=62(6 * 6)==6$

Nilai Ls sebesar 6 berarti bahwa rata-rata calon pemilih berada dalam sistem antrian TPS sebanyak 6 orang Banyak antrian pada suatu sistem pelayanan terdiri dari 6 orang, 1 loket operator pemanggilan antrian dengan 1 opertator pendata. Berikut penyelesaiannya berupa tabel waktu dalam antrian:

Tabel 1. Pengurutan Antrian Dalam Mendata Dan Pemanggil Nomor Antrian

\begin{tabular}{|l|l|l|}
\hline No Antrian & Operator & Panitia \\
\hline 1 & 1 & 1 \\
\hline 2 & 1 & 2 \\
\hline 3 & 1 & 1 \\
\hline 4 & 1 & 2 \\
\hline 5 & 1 & 1 \\
\hline 6 & 1 & 2 \\
\hline
\end{tabular}






Gambar 3. Struktur Umum Model Antrian

Sumber input yang menghadirkan kedatangan calon pemilih bagi sebuah pelayanan memiliki tiga karekteristik utama, yaitu ukuran populasi, perilaku kedatangan dan pola kedatangan (distribusi statistik). Ukuran populasi kedatangan dapat terbatas atau tidak terbatas. Sebuah populasi dapat dikatakan sebagai populasi terbatas apabila antrian yang terjadi hanya pengguna pelayanan potensial dengan jumlah terbatas. Sedangkan populasi yang tidak terbatas terjadi apabila dalam antrian pengguna pelayanan yang jumlahnya tidak terbatas seringdatang dan meminta pelayanan. Kedatangan akan dianggap kedatangan acak bila kedatangan tidak terikat satu sama lain dan kejadian tersebut tidak dapat diramalkan secara tepat. Dalam permasalahan antrian, kedatangan setiap unit, waktu dapat diperkirakan oleh sebuah distribusi peluang yang disebut distribusi poisson.

Use case diagram menggambarkan bagaimana interaksi antara sekelompok proses dengan sekelompok aktor, menggambarkan fungsi dari sebuah sistem yang akan dibangun dan bagaimana sebuah sistem berinteraksi dengan penggunanya. Use case diagram menggambarkan efek fungsionalitas oleh sistem[7].

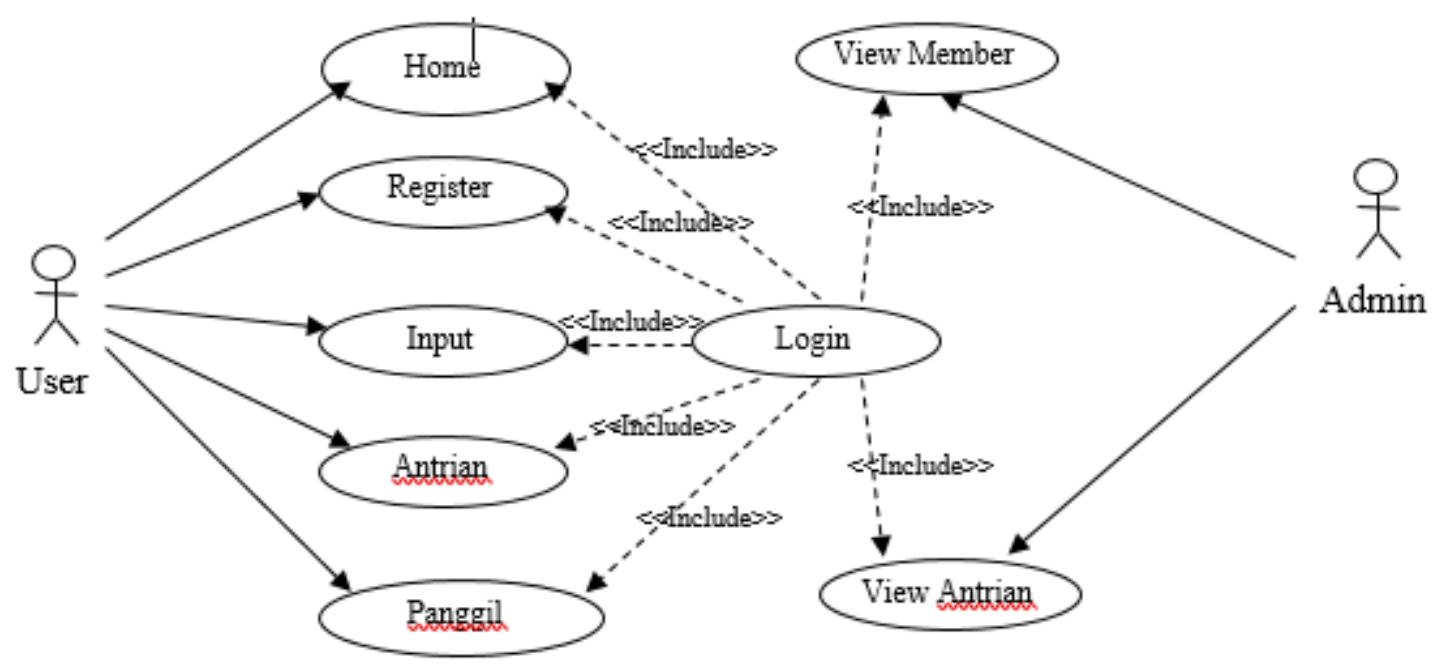

Gambar 4. Perancangan Sistem Use Case

Activity diagram menggambarkan proses-proses yang terjadi mulai aktivitas dimulai sampai aktivitas tahap penyelesaian sistem pelayanan antrian TPS[8]. 




\section{Hasil dan Pembahasan}

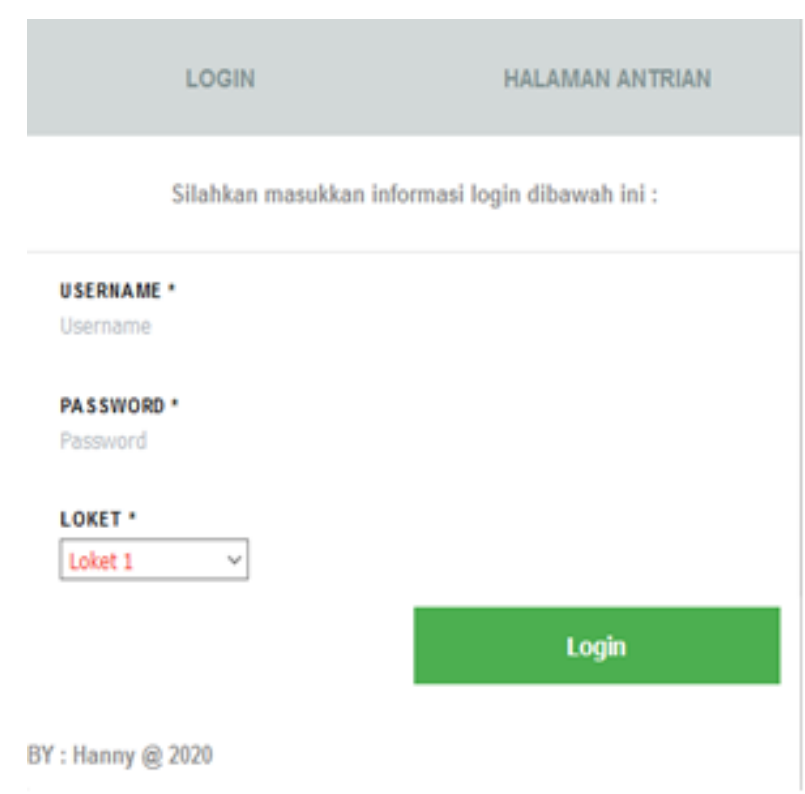

Gambar 6. Tampilan Login Operator

Dari desain tampilan login diatas dijelaskan bahwa sistem login memberikan akses ke menu utama pengguna yang telah mendaftarkan diri pada aplikasi sistem, dan mendapatkan username dan password. kemudian penguna menginput data user dan password dan memiliki kategori loket registrasi atau loket pemanggil antrian yang diberikan akses oleh admin website antrian. 


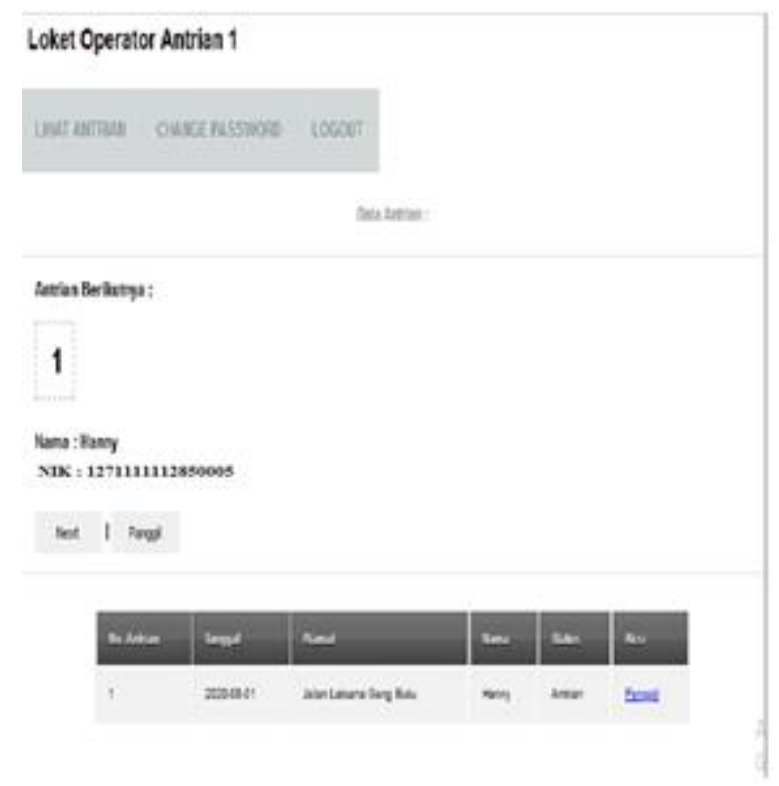

Gambar 7. Tampilan Operator Antrian

Pada loket operator antrian pendata yang telah terdaftar pada sistem loket pendaftaran maka akan dipanggil oleh operator antrian untuk dipanggil nomor antriannya yang telah terdaftar, dengan menekan tombol panggil maka menampilkan nomor antrian dengan suara nomor panggilan yang terdaftar. Pada panggilan antrian ini dapat mengatur nomor berapa yang dipanggil bisa juga melewati nomor antrian yang dipanggil sesuai dengan keadaan pada saat antrian itu terlaksanakan.

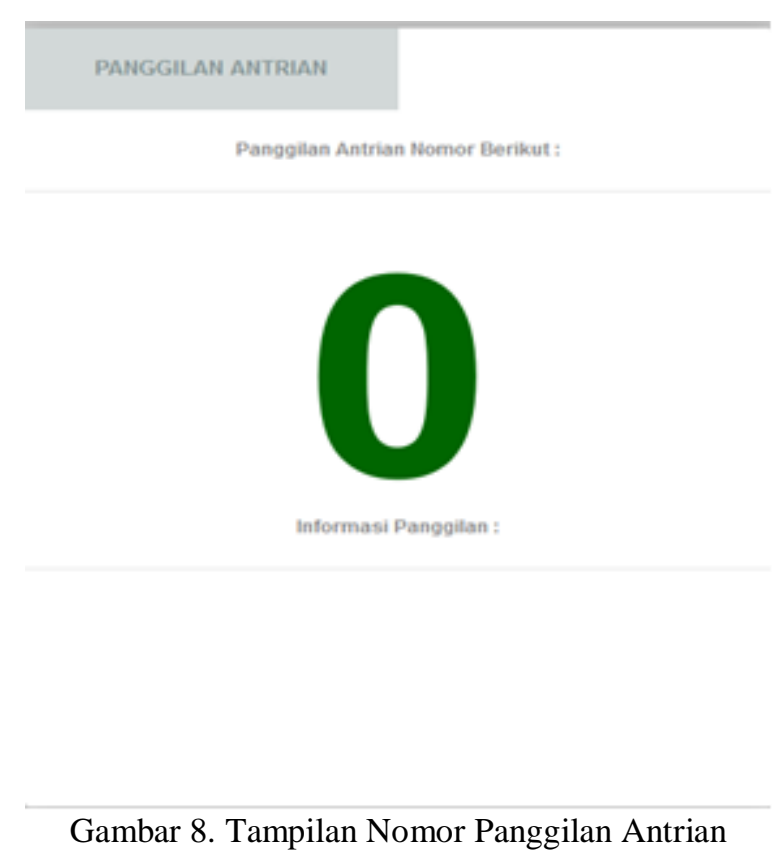

Pada tampilan desain papan nomor panggilan antrian dapat dijelaskan bahwa sistem nomor panggilan antrian yang akan tampil pada sistem antrian bila operator sistem akan melakukan pemanggilan penguna yang akan melakukan pencoblosan dengan metode single channel atau single phase.

\section{Kesimpulan}

Berdasarkan hasil pembahasan yang telah dibahas pada bab-bab sebelumnya, maka penulis dapat menyimpulkan : 
1. Menghasilkan sistem antrian yang dapat mendaftarkan calon peserta pemilu dengan sistem antrian.

2. Penelitian sistem antrian peserta pemilihan ini mengunakan metode single channel single phase.

3. Sistem aplikasi sistem antrians ini dibangun menggunakan pemrogramman PHP (hypertext processor) dan database MySQL menggunakan software XAMPP.

Adapun saran-saran yang akan diusulkan adalah Sistem ini masih mengunakan aplikasi sistem website agar kedepannya diharapkan lebih baik lagi dikembangkan dengan sistem aplikasi mobile phone berbasis android.

\section{Daftar Pustaka}

[1] S. Wijayanto, "Analisa perancangan model sistem monitoring, pencatatan dan pengiriman hasil produksi truk dengan Remote File Transfer System (RFTS) pada perusahaan XYZ menggunakan metode System Development Life Cycle," J. Nas. Komputasi dan Teknol. Inf., vol. 3, no. 1, pp. 1-8, 2020.

[2] P. Ardella and P. M. Hasugian, "Penerapan Metode Weight Product (WP) Untuk Menentukan Pengalokasian Pendistribusian Telur Terbaik Di Kecamatan Pantai Labu," J. Nas. Komputasi dan Teknol. Inf., vol. 4, no. 1, 2021.

[3] A. A. F. Amarta and I. G. Anugrah, "Implementasi Agile Scrum Dengan Menggunakan Trello Sebagai Manajemen Proyek Di PT Andromedia,” J. Nas. Komputasi dan Teknol. Inf., vol. 4, no. 6, pp. 528-534, 2021.

[4] M. Munawir et al., "Penerapan Sistem Informasi Pendataan Penerima Dana Program Keluarga Harapan pada Gampong Beurawe Kecamatan Kuta Alam berbasis Web GIS,” J. Serambi Eng., vol. 6, no. 3, 2021.

[5] T. Hidayat, Z. Zulfan, M. Munawir, and S. Susmanto, "Perbandingan Metode Antrian Paket HTB dan EDCA Untuk Layanan Multimedia Pada WLAN IEEE 802.11 n,” J. Nas. Komputasi dan Teknol. Inf., vol. 3, no. 2, pp. 132-143, 2020.

[6] S. Susmanto, M. Munawir, E. Erdiwansyah, Z. Zulfan, and D. Setiyadi, "Perancangan E-Voting pemilihan Kepala Desa untuk Transparansi Informasi di Kecamatan Lueng Bata Kota Banda Aceh," J. Serambi Eng., vol. 7, no. 1, 2022.

[7] S. Safril, Z. Zulfan, and D. Satria, "SISTEM INFORMASI RINCIAN PERBAIKAN ALAT BERAT TERINTEGRASI SISTEM NOTIFIKASI BERBASIS LAYANAN GSM (Global System for Mobile Communication) PADA CV. CIPTA KARYA GROUP," Karya Ilm. Fak. Tek., vol. 1, no. 1, pp. 7-14, 2021.

[8] D. Satria, S. Yana, E. Yusibani, and S. Syahreza, "Zulfan, 'Implementation of the SMS gateway in the flood early warning information system for village warning and community information," Int. J. Eng. Adv. Technol, vol. 8, no. 6, pp. 4005-4009, 2019.

[9] Y. G. Nengsih, "Optimalisasi Antrian Menggunakan Metode Single Channel Single Phase ( Studi Kasus DR . Reksodiwiryo Padang ) Struktur Antrian 1. Single channel - single phase pelayanan . Sedangkan single phase adalah hanya memiliki satu stasiun pelayanan antrian yang ha," J. Ilm. Perekam Dan Inf. Kesehat. Imelda, vol. 5, no. 1, pp. 30-39, 2020, [Online]. Available: https://jurnal.uimedan.ac.id/index.php/JIPIKI/article/view/356.

[10] Devi Yuliana, Julius Santony, and Sumijan, "Model Antrian Multi Channel Single Phase Berdasarkan Pola Kedatangan Pasien untuk Pengambilan Obat di Apotik," J. Inf. Teknol., vol. 1, no. 4, pp. 7-11, 2019, doi: $10.37034 /$ jidt.v1i4.12.

[11] D. Nurfitria, N. Nureni, and I. T. Utami, “Analisis Antrian Dengan Model Single Channel Single Phase Service Pada Stasiun Pengisian Bahan Bakar Umum (Spbu) I Gusti Ngurahrai Palu,” J. Sci. Pinisi, vol. 3, no. 1, pp. 65-71, 2017, doi: 10.22487/2540766x.2015.v12.i2.7906.

[12] R. A. Saputra, Parjito, and A. Wantoro, "Implementasi Metode Jeckson Network Queue Pada Pemodelan Sistem Antrian Booking Pelayanan Car,” J. Teknol. dan Sist. Inf., vol. 1, no. 2, pp. 80-86, 2020, doi: https://doi.org/10.33365/jtsi.v1i2.433.

[13] M. Ary, "Pendekatan Teori Antrian Single Channel Single Phase Pada Pelayanan Administrasi," Infotronik J. Teknol. Inf. dan Elektron., vol. 3, no. 1, p. 21, 2018, doi: 10.32897/infotronik.2018.3.1.85.

[14] Muhammad H. C. Roziq and T. Aspiranti, "Analisis Sistem Antrian Lookmansbarbier Menggunakan Model Channel Phase System untuk Meminimumkan Waktu Tunggu dari tingkat kepuasan konsumen Pada umumnya konsumen yang merasa tidak puas 2 . Bagaimana menentukan Sistem Antrian Alternatif LooksmanBarbier," Pros. Manaj. Spes., pp. 1028-1036, 2018, [Online]. Available: http://karyailmiah.unisba.ac.id/index.php/manajemen/article/view/12433.

[15] S. I. Lestari and A. Suseno, "Analisis Antrian Menggunakan Metode Single Channel Single Phase Pada Klinik Adinda," Syntax Lit. J. Ilm. Indones., vol. 4, no. 1, pp. 1-2, 2021, [Online]. Available: https://jurnal.syntaxliterate.co.id/index.php/syntax-literate/article/view/3558. 